\title{
Responses to indirect complaints as restricted activities in Therapeutic Community meetings ${ }^{1}$ Marco Pino ${ }^{2}$
}

\begin{abstract}
In this chapter I investigate how the staff members of a mental health Therapeutic Community in Italy avoid displays of affiliation in response to residents' indirect (or third party) complaints. I show how this restriction can be embodied in different practices: ignoring a resident's turn carrying a possible complaint, avoiding attending the complaint-components of a resident's turn, and disaffiliating with a resident's complaint. I also discuss a deviant case in which affiliation is produced and is later treated by the staff members as a problematic stance to be produced following a resident's complaint. I argue that through a restriction on affiliation the staff members implement the institutionally-relevant identity of intermediaries, whose task is to encourage the residents' compliance to the decisions of absent third parties.
\end{abstract}

\section{Acknowledgment}

I wish to thank the editors and three anonymous reviewers for their useful comments on earlier versions of this chapter.

\footnotetext{
${ }^{1}$ Pre-print copy of Pino, M. (2015). Responses to indirect complaints as restricted activities in Therapeutic Community meetings. In F. H. G. Chevalier and J. Moore (Eds.) Producing and Managing Restricted Activities: avoidance and withholding in institutional interaction, pp. 271-303. John Benjamins. DOI: 10.1075/pbns.225.09pin

${ }^{2}$ Sue Ryder Centre for the Study of Supportive, Palliative and End of Life Care

School of Health Sciences

University of Nottingham

B Floor, Queen's Medical Centre, Nottingham, NG7 2HA.

Tel: +44 1158230494

Email:marco.pino75@gmail.com
} 


\section{Introduction}

Complaining has been granted considerable attention in the research literature and there is now a body of evidence on how complaint sequences are carried out by participants both in mundane interaction (Laforest 2009; Monzoni 2008; Schegloff 1988; Traverso 2009) and in more institutionalized settings (Heinemann 2009; Monzoni 2008; Monzoni 2009; Ruusuvuori and Lindfors 2009; Stokoe 2009). Heinemann and Traverso define complaining as the activity of "express[ing] feelings of discontent about some state of affairs, for which responsibility can be attributed to 'someone' (to some person, organization or the like)" (2009, 2381). A major distinction has been drawn between direct complaints (Dersley and Wootton 2000; Laforest 2009; Monzoni 2009) and indirect complaints (Drew 1998; Drew and Walker 2009; Ruusuvuori and Lindfors 2009; Traverso 2009). In this chapter, I focus on responses to indirect complaints. Through indirect complaints, speakers disclose their negative stance about some state of affairs of personal relevance, for which responsibility can be attributed to a third party. Heinemann and Traverso observe that "by exposing their inner state in this manner, complainants make themselves vulnerable to how others react" $(2009,2381)$ : recipients can resist aligning to their co-participants' complaints for various reasons, such as avoiding siding with either the complainant or the target of the complaint (Mandelbaum 1991/1992). Not surprisingly, this way of handling complaints is found in institutional interactions, where interactants guided by their institutional roles can be particularly cautious about receiving complaints about third parties (Heinemann and Traverso 2009). For instance, they can maintain a neutral stance toward clients' complaints, as Ruusuvuori and Lindfors (2009) show with respect to medical general practice, where doctors frequently ignore the complaint-implicative aspects of patients' problem presentations. In these cases, doctors restrict themselves to the practical business of dealing with patients' health problems and they avoid attending to patients' reported experiences about mistreatments that they suffered in encounters with other health professionals. However, health professionals can also affiliate or disaffiliate with their clients' complaints about third parties. These types of stance displays have been analysed as vehicles to build and maintain rapport (Ruusuvuori and Lindfors 2009) or relational distance (Heinemann 2009) between professionals and clients.

In this chapter, I also consider responses to indirect (or third party) complaints as a means of building and managing institutionally-relevant relationships and identities in a particular service: a Therapeutic Community (TC) providing mental health rehabilitation. In this service, located in Italy, a staff of mental health professionals (nurses, care workers and one educator) provides support for people diagnosed with different types of mental illness (schizophrenia for the most part). These people (residents henceforth) undergo a rehabilitation programme, aimed to help them acquire or regain competences to cope with everyday life (for an overview see Crescentini, De Felice and Tonzar 2004). My research focuses on meetings where, on a weekly basis, the staff members and the residents sit around a big table in the lunchroom and talk. These meetings are regularly attended by staff members Barbara and Massimo, who engage in different types of activities, such as: (a) eliciting tellings of recent events (see the 'The letter' example in extract 2); (b) announcing and planning future activities (see the 'Easter' example in extracts 1a-1c); (c) inquiring about problems concerning the management of routines and activities at the TC (see the 'Medication' example in extracts 3a-3c). Residents' indirect complaints can emerge in the course of all these activities. Through this type of complaints, the residents report a negative state of affairs whose responsibility can be attributed to a third party, namely, a party different from the recipients of the complaint. Indirect complaints are one among a group of action-types that the residents employ to bring their difficulties to the staff members' attention. The staff members' responses to the residents' indirect complaints are a vehicle by which they carry out one of their core institutional remits: listening to the residents' troubles and supporting them. In this chapter I explore how they implement this task. My central argument is that the staff members' interactional conduct exhibits an orientation to affiliation as a practice that should be avoided in response to residents' 
indirect complaints. I will refer to this phenomenon as a restriction on affiliation. By this, I mean specifically that the staff members work to avoid displaying a stance or evaluation that agrees with, embraces or otherwise supports the residents' evaluations of the state of affairs targeted by their complaints.

In terms of the distinction between withholding and avoidance outlined in the introduction to the present volume (Chevalier and Moore, this volume), the phenomenon described in this chapter can be considered as a form of avoidance. As a matter of fact, the staff members do not appear to withhold affiliation as a response made sequentially-due by the residents' indirect complaints. It is more accurate to say that the staff members systematically avoid affiliation as one of the available, possible responses to the residents' indirect complaints, which can nevertheless be relevantly addressed through other types of response (see Schegloff 2007, 61). Affiliation is possible but not sequentially due, strictly speaking (Chevalier and Moore, this volume; but see Weatherall, this volume, for cases where the professional participants appear to be withholding affiliation as a sequentially-due response to the lay participants' complaints).

The chapter is organised as follows. After an illustration of the data set, I describe three different ways in which the staff members avoid affiliating with the residents' indirect complaints. I show that through the avoidance of affiliation the staff members manage the activity of responding to the residents' indirect complaints as restricted (Chevalier and Moore, this volume). I argue that the proposed restriction does not reflect pre-existing policies or guidelines that ban the staff members from affiliating with the residents. Rather, the avoidance of affiliation appears to be a vehicle through which the staff members locally manage constraints that stem from (and reflexively implement) the socio-relational organisation of the service. Specifically, the staff members' management of responses to indirect complaints as restricted reflects and implements their role of intermediaries within the organisation of the TC. In the final section of the chapter I consider how my findings contribute to the understanding of restricted activities in institutional interaction.

\section{Data}

The data for this chapter come from the audio-recordings of 4 meetings held at the TC and attended by staff members Barbara and Massimo (and occasionally by other staff members) and by the residents (whose number varies between 8 to 10 across the recorded meetings).

A note is in order about how my collection of responses to indirect complaints was built. A methodological problem emerged when considering residents' possible complaints (Schegloff 1988; Schegloff 1996; Schegloff 2006) that are followed by staff members' turns that avoid addressing the complaint-implicative aspects of those turns (a phenomenon that receives attention in the analyses of extracts $1 \mathrm{~b}$ and 2). In some cases, although I could recognise the complaint-implicative aspects of the residents' turns, the staff members' responses failed to display an orientation to the residents' turns as complaint-implicative.

The issue of what counts as a complaint and how it can be identified is a matter of debate in the research literature (among others, Drew 1998; Edwards 2005; Schegloff 2005). Let us only consider Drew's remarks. Although they refer to the "moral work" implicit in complaint sequences, it can be brought to bear on the issue of responses that avoid taking up the complaint-implicative aspects of a turn at talk.

There seems to be no explicit recognition by either of the participants that these moral issues are present in the talk or that the speaker's detailing is offered by way of a defense. This raises a methodological question, namely, that if the moral work that we can see being done in such instances of defensive detailing is implicit and does not come to the interactional surface of the talk between the participants, how can we (as analysts) make a case for that being the work of such detailing? (Drew 1998, 302). 
Drew concludes that "this is not a question that I think can yet be answered" and selects to present "cases in which it is apparent that speakers are orienting to the possibility that some (conversational) action of theirs might be regarded as a transgression, and in their detailing, they imply the innocence of their conduct" (Drew 1998, 302). In a similar vein, I refined my collection by excluding cases where I could not have evidence that the staff members interpret a resident's turn (carrying the candidate complaint) as a complaint. This led me to identify 13 episodes of residents' indirect complaints. In the majority of them the residents produce complaint-implicative turns that do not evolve into fully-fledged complaints (Ruusuvuori and Lindfors 2009). The cases examined in this chapter fall within this category (the case of a more overt resident's complaint is examined in Pino and Mortari 2013, 212).

The complaint episodes in this collection are similar to what has been referred to as "big packages" (Jefferson 1988; Sacks 1992) or "long sequences" (Traverso 2009). The complainingactivity emerges from the preceding talk and is subsequently exposed, developed and closed down across extended stretches of talk (see also Drew and Walker 2009), in which a resident's complaint can be reasserted (and reworked) several times and be addressed by different staff members' responses. In order to allow the readers to have a sense of how these activities are carried out in their natural conversational environments, in this chapter I mainly rely on two extended examples (extracts 1a-1c and 3a-3d) to illustrate the different interactional practices that embody the proposed restriction on affiliation.

I present now three ways in which the staff members manage the proposed restriction: by ignoring residents' turns that carry possible complaints (extract 1a), by avoiding addressing the complaint-implicative aspects of those turns (extract 1b), by overtly disaffiliating with the residents' complaints (extract 1c). Then, I analyse a deviant case where affiliation to a resident's complaint is produced (extracts 3a-3d).

\section{Ignoring a resident's turn carrying a complaint}

I begin with the practice that shows the lowest grade of staff members' commitment to a resident's complaint: ignoring the resident's turn which is the carrier of a complaint. In this case, the resident does not become a ratified participant to an ongoing interaction and the relevancies otherwise projected by his turn are prevented from becoming sequentially implicative.

Massimo (Mas in the transcript) is a nurse, Barbara (Bar) an educator, and Annamaria (Ann) a care worker, all staff members (the S preceding the participants' names in the transcript is used to remind the reader of their role as staff members). The other participants are residents (the $\mathrm{R}$ preceding their names in the transcript is used to signal their status as residents): Carlo (Car), Daniele (Dan), Franco (Fra) and Mario (Mar). All the names are pseudonyms. References to places have also been altered.

Before the beginning of extract 1a, Massimo has illustrated an upcoming event: the residents will go out for lunch on Easter day, but in a different restaurant from the one they went the year before. After all the residents have been asked by Massimo and Barbara whether they are satisfied with this choice, the topic has reached a point of possible closure. Massimo's turn-initial "pero" ("but") in line 1 conveys that topic-closure is premature because there is more to be discussed: it remains to be decided who is going to the restaurant, since some of the residents might have different plans for Easter Day (lines 3-4). The symbol $\rightarrow_{\mathrm{c}}$ signals the turn carrying the complaint.

(1a) Easter

1 S-Mas però dobbiamo anche stabili:re chi è che va:?

$2 \quad$ but we 
5 R-Car

6 R-Dan

7

8 R-Car

9

10 ?

11 S-Mas

12 R-Dan

13 R-Car

14

$15 ?$

$16 \mathrm{R}-\mathrm{Car}$

17

18 R-Mar

19 R-Car

20

21 S-Bar

$22 \mathrm{~S}-\mathrm{Ann}$

23 S-Bar

$24 ?$

25

26 R-Dan

27

28 S-Bar

29

30 S-Bar

31

33 ?

34 S-Bar
32 S-Mas

perché ci sarà qualcuno che vorrà andare a ca:sa because there will be someone who wants to go ho:me quel giorno li.

that day.

infa:tt [i io vado fuori con]

indee: [d I'm going out with]

[eh io vorrei an]dare

[eh I'd like to go]

a cas [a ma mio papà non] vuole?

hom[e but my dad doesn't] want?

[con mia ma:mma,]

$(0.3)$

[with my mu:m, ]

$([)$

$[m[: h$.

[come la- come la m[ettia:mo?]

[what are- what are we [going to do about it?]

[e dopo] viene a prender-

[and later] comes to get-

$\operatorname{mia}[:$

my $[$ :

[ (vado a magna [re)

[ (I'm going to [eat)

[cioè io vado a mangiare

[ I mean I'm going out to eat

con mia zia: (0.5)

with my aunt: $(0.5)$

(perch[é)

(wh $[\mathrm{y})$

[a Larego.

[in Larego.

$(0.4)$

allora chi è che ci va?=

so who's going there?=

$=e[: h$

[(>'peta-<)? (.) che ce I'ho mi sembra [anche qua.

[ (>wait-<)? (.) I think I have it [here too.

$(0.9)$

(ma) questo è un discorso del papà che non va

(but) this is an issue with my dad that is not (goi:ng

' $\left(a[v a: n t i)^{\circ}\right.$

${ }^{\circ}$ for $[w a: r d)^{\circ}$

$(0.9)$

[Di: : :na.

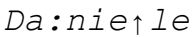

$(0.4)$

${ }^{\circ}$ e Pina? ${ }^{\circ}$

$\circ$ and Pina? ${ }^{\circ}$

$($ l $)$

[Giuseppi :na.

Massimo's turn in line 1 proposes a framework for a new activity, to "deci:de who's going:" to the restaurant on Easter Day. After a gap (line 2), he offers an account for engaging in this activity: some of the residents might want to visit their families instead (lines 3-4). While the TCU in line 1 projects the relevance of 'deciding' who is going to the restaurant, the second TCU in lines 3-4 provides the residents with an opportunity to talk about plans to visit their own families. In line 5 Carlo, one of the residents, takes up this second thread by initiating an "indeed"-prefaced turn, reporting his plan to go out with his family on Easter Day. In lines 6-7, Daniele also produces a turn that is responsive to Massimo's second TCU. It can be heard as an indirect complaint, since it 
describes a desirable outcome ("io vorrei andare a casa" ["I'd like to go home"]) that Daniele is prevented from achieving because of his father ("ma mio papà non vuole?" ["but my dad doesn't want?"]). At the same time, it can be heard as the presentation of a problem to be solved, providing for the staff members to offer help to go home on Easter Day. A feature shared by the residents' complaints in my collection is that they are hosted in turns that can be heard as performing other actions. A consequence is that the staff members can select which aspect of the turn to address, either its complaint-implicative aspect or another aspect (see Mandelbaum 1991/1992). We will see how they can manage this selection in the next section. In the case of extract 1a, the staff members avoid addressing either of the actions possibly conveyed by Daniele's turn, which they ignore altogether. In what follows, I provide evidence for this claim.

Because of the lack of a video-recording, it is not clear who is the addressee of Massimo's acknowledgement token in line 11. In line 12, Daniele pursues a response to his previous turn ("come la mettiamo?", literally "how do we put it?", idiomatically translated into "what are we going to do about it?"), while from line 13 to 19 Carlo and another resident communicate their plans for Easter Day. Up to this point, the interaction has been in a fluid state: Massimo's TCUs in lines 1 and 3-4 have opened up the possibility for multiple courses of action. The residents have addressed Massimo's second TCU, some of them by communicating plans to meet family members on Easter Day, Daniele by complaining about his father for denying him such an opportunity. Each of these actions could be subsequently addressed by the staff members. At the same time, the task made relevant by Massimo's first TCU in line 1 is also pending and this is precisely the thread that Barbara, another staff member, takes up in line 21. The turn initial "allora" exhibits the same pragmatic function of the turn beginning 'so' in English conversation, where it is used "to show that the current utterance is occasioned by something other than the immediately preceding talk" (Bolden 2009, 996). Barbara's turn links back to Massimo's first TCU in line 1 and takes up the task that it made relevant. By so doing, her turn reflexively constitutes the talk from line 5 to 19 as non-relevant to the task at hand (deciding who is going to the restaurant on Easter Day). A consequence of this choice is to leave Daniele's complaint unaddressed.

The opportunity of avoiding addressing Daniele's turn is provided for by some features of the sequential environment. After Massimo's initial turn, more than one resident take turns in an environment where there are likely to be multiple parallel conversations going on (lines 5 through 19). In this context, Barbara's turn in line 21 can be heard as a move to bring the conversation back 'on track'. Ignoring Daniele's complaint might be part of an overall move, at this juncture in the interaction, to treat all the residents' interventions as non-relevant to the task at hand and to restore a turn-taking procedure that allocates turns to only one speaker at a time, avoiding parallel, simultaneous conversations. At the same time, though, ignoring Daniele's complaint does not seem as the mere by-product of a contingent concern with the management of an activity in progress. It becomes available only later in the encounter (see extracts $1 \mathrm{~b}$ and 1c) that the staff members are at the very least reluctant to accept Daniele's complaint about his father. Before turning to these developments, I provide further evidence that the staff members' conduct can be characterised as 'ignoring' Daniele's complaint.

A distinction needs to be drawn between Carlo's and Daniele's actions. Carlo's turn, which communicates his plan for Easter Day, makes relevant a confirmation, which might be delivered by Massimo from lines 16 to 20 through a nod. Since a video-recording for this encounter is not available, we do not know that. Daniele's turn (lines 6-7) is a different matter. Daniele's turn makes relevant more than a confirmation; it provides for the staff members either to express their own stance regarding the complained-of matter (the fact that Daniele's father does not want him to go home) or to proffer a remedy, e.g. by suggesting a way in which he could fulfil his desire to go home. That a response is relevantly missing after Daniele's turn in lines 6-7 is indexed in Daniele's turn in line 12, which pursues a response beyond the mere claim of epistemic access that a nod would allow (Stivers 2008). At the point where Barbara enters the interaction in line 21, it is safe to say that Daniele's turns $(6-7,12)$ have been ignored. 
Further evidence that Daniele's contributions are ignored is provided in what happens next. Barbara pulls a list (line 23) containing the names of the residents who are supposed to go to the restaurant on Easter Day (and who will not be joining their families that day). There is a gap in line 25, after which Daniele issues a new version of the complaint (lines 26-27). In overlap, Barbara starts to read the list of residents who have already been considered as candidates for the lunch at the restaurant (the list was written before the beginning of the encounter). In line 30, Daniele is mentioned among the residents who are going to the restaurant with the staff members on Easter Day, thus confirming that his personal preference to go home is not being considered at this point of the interaction. ${ }^{1}$ A consequence of ignoring Daniele's turns is that the activity undertaken from lines 21 to 34 can be designed without taking into account his complaint. The later developments shown in extracts $1 \mathrm{~b}$ and $1 \mathrm{c}$ demonstrate that his complaint has, nonetheless, been heard.

The practice examined in this section enables the staff members to carry out the practical business of an ongoing activity (making arrangements for a future event) without taking into account a complaint that it occasions. This is one among a set of practices that enable the staff members to locally manage a restriction on affiliation to indirect complaints: by ignoring Daniele's complaint, the staff members can avoid providing their own stance on the complained-of matter altogether.

\section{Avoiding attending the complaint-components of a resident's turn}

This section illustrates another practice that allows the staff members to avoid addressing a resident's complaint. Instead of ignoring the resident's turn altogether, they address the resident's turn as the carrier of another action, not as the carrier of a complaint. The resident's turn is successful in launching a sequence, but it is not a complaint sequence. I describe one interactional device used to achieve this outcome: proposing a remedy for the resident's 'problem'.

The following extract starts approximately 1.5 minutes after the end of extract 1a. At the beginning of the extract, the participants are still engaged in talk about the upcoming Easter Day. From line 1 to 4, two residents' plans to go home are summarized. From line 7 to 13 another resident, Gianni negotiates with Massimo the possibility of asking his brother to go home on Easter Day. In a way similar to extract 1a, Daniele's turn at line 18 occurs in an environment where talk about plans to go home on Easter Day is relevant.

(1b) Easter

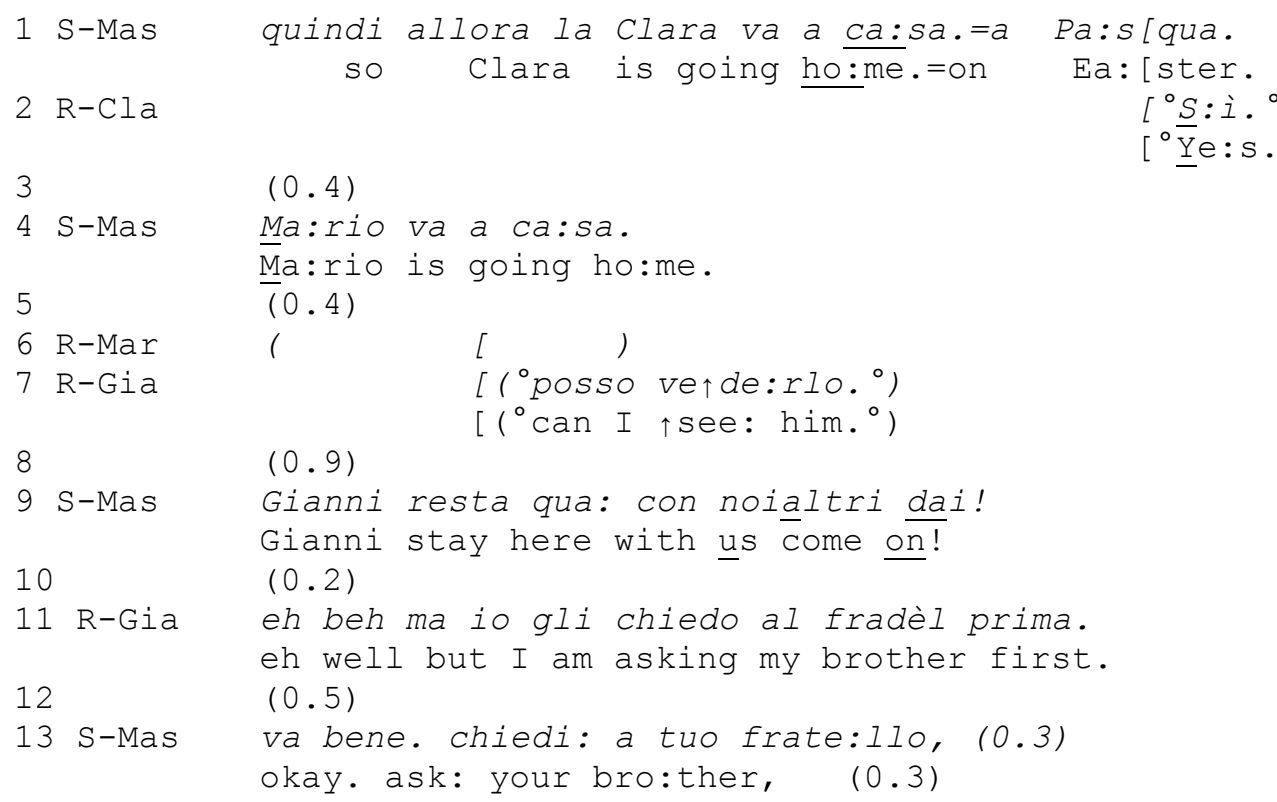




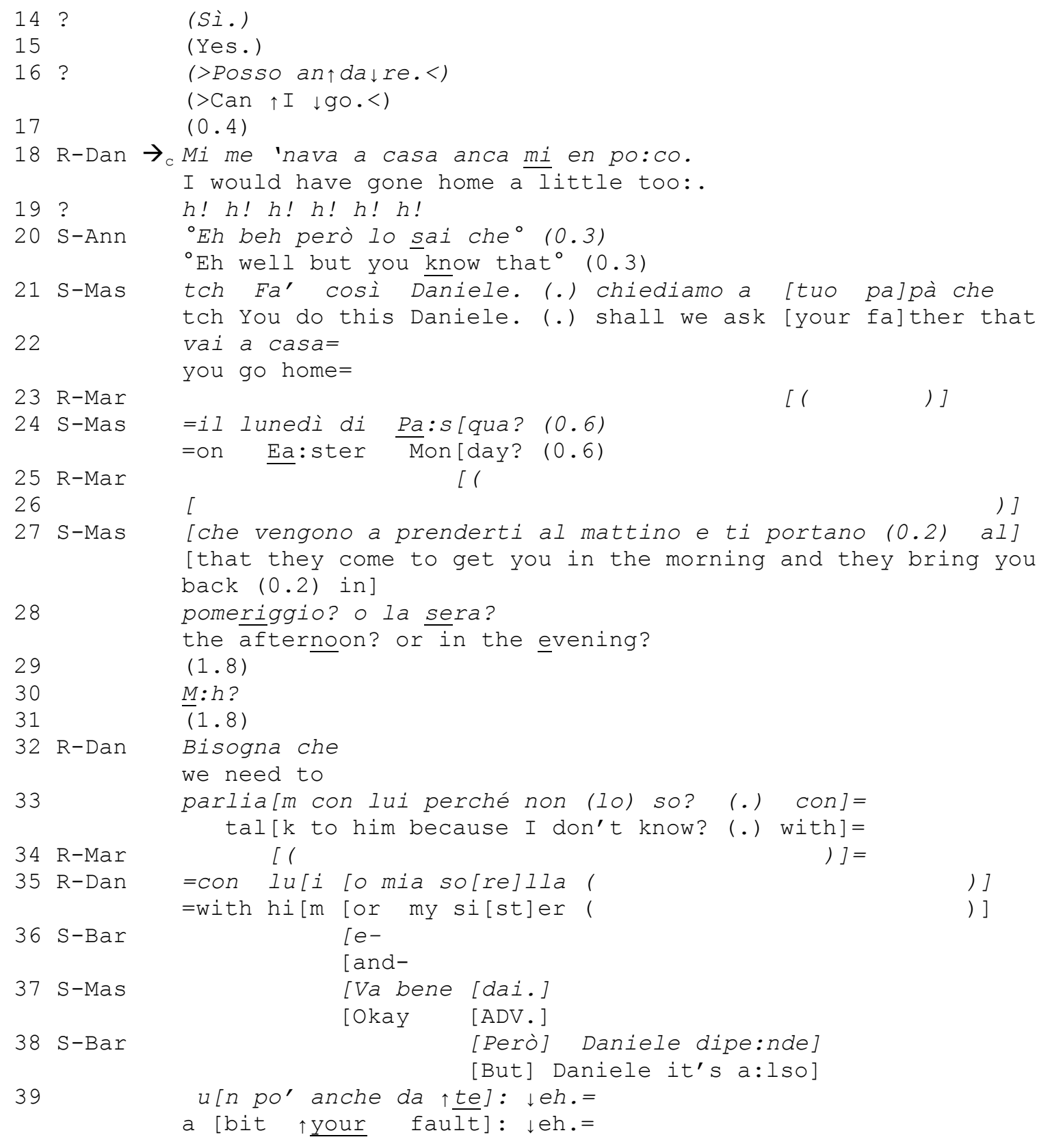

Due to its appearance in a conversational context occupied by requests to go home (see lines 7-16), Daniele's turn in line 18 can be heard as the presentation of a problem or obstacle (his inability to go home) and, hence, can make relevant in next position an offer of help to solve the matter. However, two aspects of its design make available at least another understanding of its possible interactional import. Firstly, the verb mood and tense: Daniele employs the dialectal construction "mi me "nava", in which the imperfetto tense of the indicative ("andavo" ["I-went"] in Italian) corresponds to the past tense of the conditional mood in standard Italian ("sarei andato" ["I would have gone"]). Its use conveys a sense of impossibility or preclusion: going home on Easter Day is not an available option for him anymore. In light of the fact that Daniele has already lamented that his father does not want him to go home (see extract 1a), this turn can be heard as renewing that complaint. A second feature that contributes to the understanding of this turn as doing complaining is the comparative dimension built into its design. By saying that he would have liked to go home "too" (dialectal "anca mi" ["me too"]), Daniele displays an orientation to a difference between his own situation and that of the other (more privileged) residents who are allowed to go home. Taken together with the mournful intonation (hearable on tape) with which the turn in line 18 
is uttered, this feature highlights Daniele's inability to go home as an unfortunate and unjust treatment.

These complaint-implicative features are embedded in a turn that can be heard as also performing a problem presentation. It is the latter aspect of the turn that Massimo addresses in extract $1 \mathrm{~b}$. Nevertheless, Massimo also displays some orientation to the fact that a complaint is possibly 'in the air' and, as I argue in what follows, Massimo's response might be deployed in order to prevent it from evolving into a fully-fledged complaint.

In line 20, Annamaria, a care worker, starts a well-prefaced response to Daniele's turn, which projects a non-straightforward and disaffiliative response (Schegloff and Lerner 2009). Annamaria's turn remains incomplete as its intra-turn pause is occupied by the start of Massimo's response (line 21). The first TCU ("tch fa cosi Daniele." ["tch you do this Daniele."]) projects the response as delivering a remedy and thus reflexively treats Daniele's turn as presenting a 'problem to be solved' (not to a complaint; see Weatherall, this volume). The proffered remedy consists of proposing that Daniele goes home the day after Easter (lines 21-22, 24). It is followed by a 0.6 seconds gap (line 24), in which talk by another resident can be heard in the background (lines 2526) and where a response by Daniele is not forthcoming. Massimo elaborates on his proposal, suggesting that Daniele's relatives could pick him up in the morning and then bring him back to the TC in the afternoon or in the evening (lines 27-28). The rising intonation invites a response by Daniele which, after the 1.8 seconds gap in line 29, Massimo pursues by deploying the token "m:h" with marked rising intonation (30).

There is a sense of urgency in how Massimo manages the sequence. The gap in line 31 is a space where Daniele is put under considerable pressure to provide a response. Daniele avoids either accepting or rejecting the proposal by producing a hedging response (32-33), which makes its feasibility contingent on what his father will have to say. When he further expands his turn (35) both Barbara (36) and Massimo (37) start in overlap. The object deployed by Massimo in line 37 is a sequence-closing third (Schegloff 2007). It comes after Daniele has completed two TCUs (32-33) and at a point where he is proceeding to further expand his response. Despite the fact that Daniele's uptake of Massimo's proposal up-to-this-point is at best analysable as a very hesitant, if not sceptical, acceptance, Massimo treats it as sufficient to propose sequence-closure. The urgency with which Massimo moves to sequence-closure might be motivated by the pressure to go back to the business of making preparations for Easter Day. However, I argue for another possibility: Massimo might be preventing the re-introduction of Daniele's complaint about his father. I rely on two types of evidence for this claim: detailed analysis of this extract and comparison to other instances in my collection.

Firstly, detailed examination of this exchange provides evidence of Massimo's orientation to a complaint embedded in Daniele's turn. By proposing that Daniele goes home on Easter Monday, Massimo implicitly acknowledges that going home on Easter Day is not an available option for him anymore. Furthermore, by making the possible success of the proposed remedy contingent on Daniele's father's cooperation, Massimo displays that he heard the complaint when it was first articulated (see extract 1a) and acknowledges, albeit implicitly, that the problem presented by Daniele involves the responsibility of a third party. Someone else's agency is relevant for the understanding of the structure of the problem and for the design of a possible solution. Massimo's response, thus, indexes his understanding of Daniele's turn as embedding a complaint-implicative aspect: an attribution of responsibility (Heinemann and Traverso 2009).

Furthermore, Massimo's response displays an orientation to Daniele's turn in line 18 as making available that he suffered a mistreatment (another complaint-implicative feature), specifically that he was deprived of something valuable. The design of Massimo's response makes it hearable as a sort of 'compensation'. By employing the plural form of the verb 'to ask' (line 21: "chiediamo"), Massimo co-implicates himself in the future course of action that might solve Daniele's problem. This sense of involvement in Daniele's predicament suggests that Massimo implicitly recognizes that Daniele's negative feeling is (at least partially) warranted and that it 
should be dealt with somehow. The compensatory sense of his proposal is also retrievable in the nature of the proposal itself: going home the day after Easter, instead of Easter Day.

To summarize, Massimo's response (lines 21, 22, 24, 27-28) addresses Daniele's problem presentation. It does so by delivering a sequentially relevant and affiliative response: a remedy offer. However, it exhibits an orientation to the complaint-implicative elements of Daniele's turn and it seems to exploit the properties of the remedy-offer (specifically, its closure-relevance) in order to bring the sequence to a close as soon as possible, preventing Daniele from re-issuing his complaint.

The claim that Massimo's remedy offer is deployed not only to relevantly and appropriately address Daniele's problem presentation, but also as a way of curtailing its progression into a fullyfledged complaint, is supported by reference to other cases in my collection. In the following extract another resident, Dina, reports a problem to Massimo.

(2) The letter

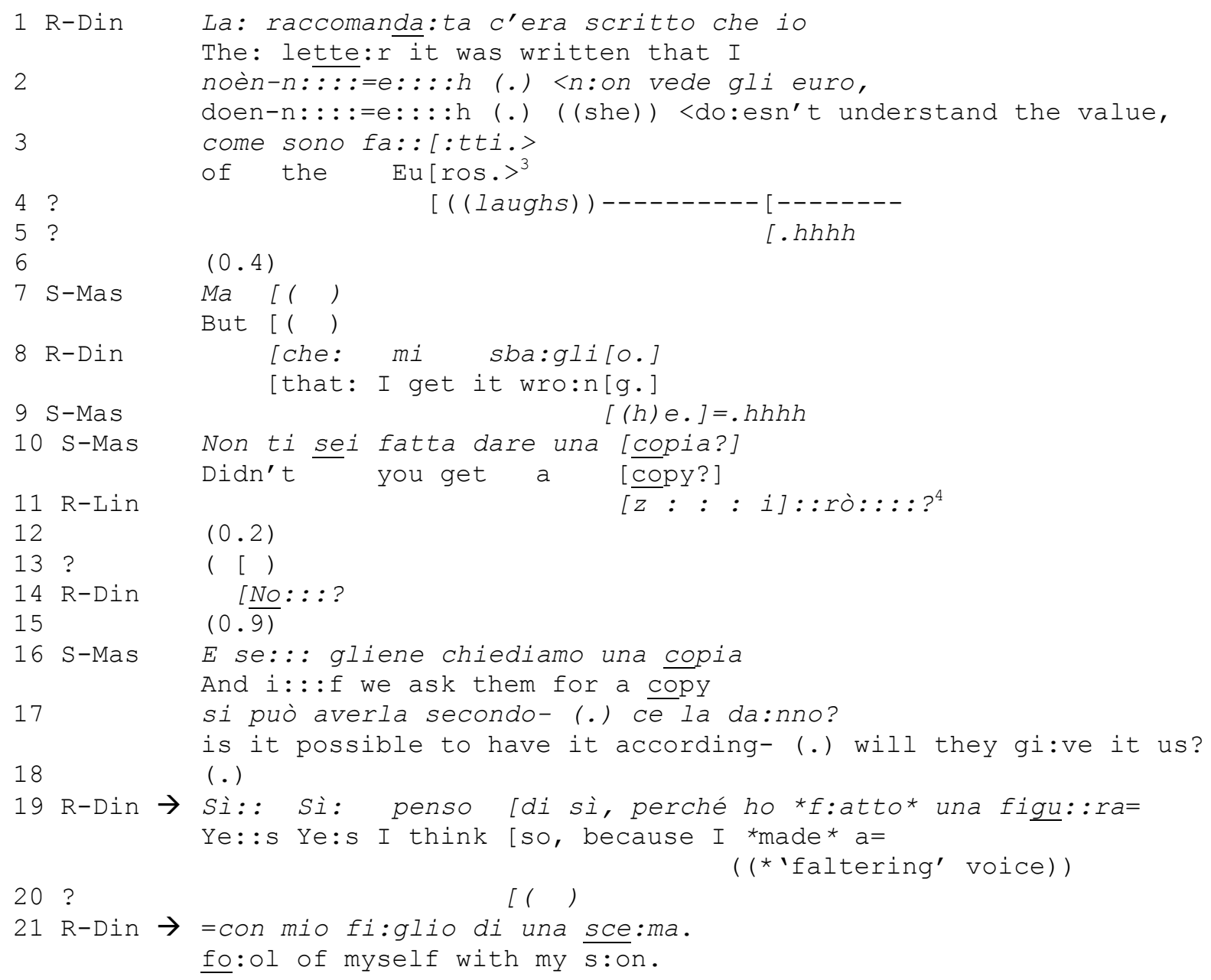

Dina reports that, when she last went to visit her family, she was shown a document that attributes to her a form of disability (lines 1-3). Dina's turn is hearable as embedding a complaintaspect (unpacked in a later segment of the conversation, not shown in this chapter; see Pino and Mortari 2013): a document was sent to her family (presumably by a medical board) that contains sensitive and negatively-valued observations about her (lines 2-3, 8). However, like in extract 1b, the resident's turn lends itself to be treated as a problem presentation and this is what Massimo does by deploying the preliminary to a solution (lines 16-17, the implication being that, if the staff members could read the letter, they might be able to do something; like in extract $1 \mathrm{~b}$, the use of "we" makes the proposal sound as a collaborative effort to deal with the problem). Dina accepts the 
proposal in line 19, but then she goes on to elaborate on the negative effects of the reported event, thus upgrading its complainable nature (see Weatherall, this volume). This example illustrates that the complaint-implicative aspects of a problem presentation can be expanded (and upgraded) in the sequential place after a remedy proposal. In extract $1 b$, it is possible that Massimo accelerates sequence-closure with an orientation to this sequential position as a slot vulnerable to the reintroduction of Daniele's complaint.

There is a third source of evidence for the possibility that Massimo hears Daniele's turn as complaint-implicative: Barbara's subsequent response in lines 38-39 of extract 1b clearly targets the complaint embedded in Daniele's problem presentation.

To summarize, there is evidence suggesting that Massimo's response in extract $1 \mathrm{~b}$ might be designed to exploit the closure-implicativeness of the remedy-offer that it delivers, in order to prevent a resident's turn from evolving into a fully-fledged complaint. This, I argue, is another way of managing responses to the residents' indirect complaints as restricted activities. Massimo's response is affiliative with respect to Daniele's problem presentation, to which it offers a remedy, but it avoids addressing the possible complaint that the turn in line 18 performs. By so doing, Massimo can avoid providing his own stance about the issue regarding Daniele's father and his unwillingness to let him come home for a visit. By virtue of its being addressed to Daniele's turn as a 'problem to be solved' (not as a complaint), Massimo's response does not commit him to either affiliate or disaffiliate with Daniele's complaint about his father.

\section{Summary and comment}

I have illustrated two practices that the staff members employ to avoid addressing the relevancies projected by the complaint-components of residents' turns. Taken in isolation, these cases are compatible with a restriction on complaint-recipientship. In other words, the staff members could be reluctant to communicate their stance (either affiliative or disaffiliative) toward the residents' complaints about third parties. However, examination of my data set shows that the staff members also deliver disaffiliative responses to the residents' indirect complaints. This phenomenon, which is examined in the next sections of this chapter, contributes to the understanding of the staff members' interactional conduct as being informed by a more specific type of restriction: not a restriction on complaint-recipientship per se, but a restriction on affiliative complaint-recipientship. In this light, the practices examined so far constitute only one possibility of implementing the proposed restriction. This raises the issue of why, on certain occasions, the staff members withhold complaint-recipientship (as in the cases examined so far), while in others they provide a disaffiliative stance. I reserve this issue for the concluding discussion and I turn now to the staff members' disaffiliative responses to the residents' complaints.

\section{Disaffiliating with a resident's complaint}

In extract 1c, which directly follows on from extract $1 \mathrm{~b}$, a second staff member, Barbara, addresses Daniele's complaint (see line 18 of extract $1 \mathrm{~b}$ ) and initiates a series of actions designed to undermine it. I characterise as 'undermining' practices that are deployed to expose the untenability of a resident's complaint.

(1c) Easter

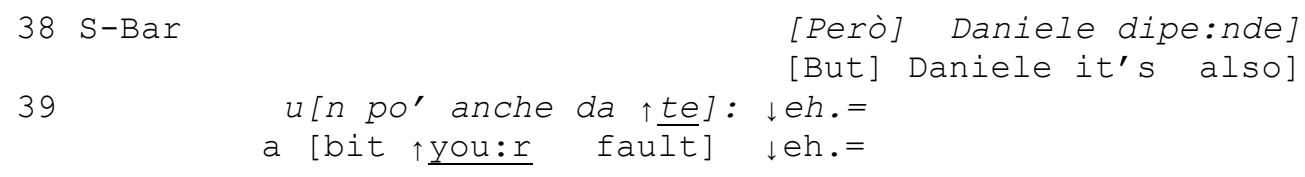




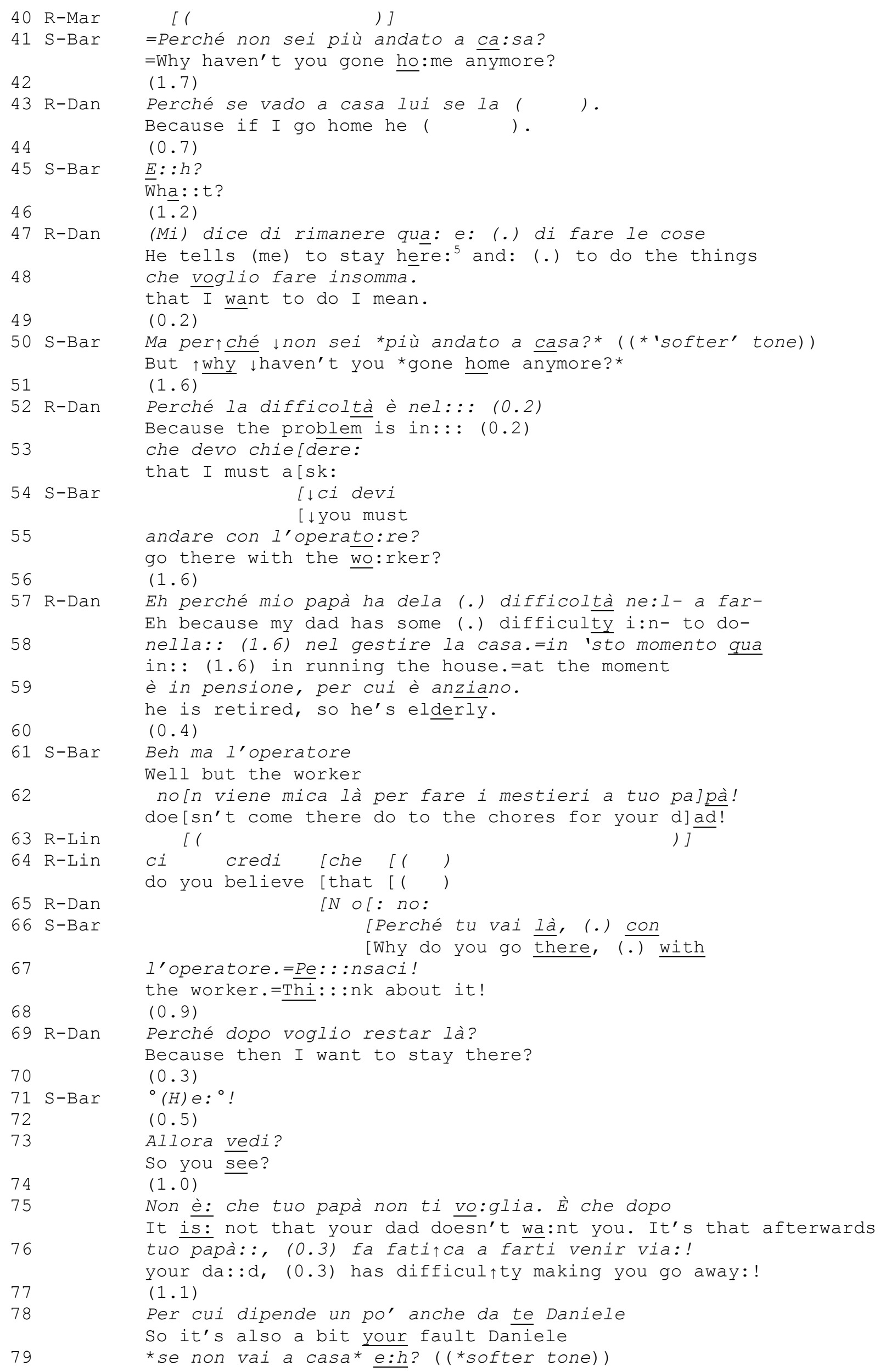


While Massimo has moved toward sequence-closure (extract 1b, line 37), Barbara maintains the sequence open by addressing Daniele's turn (extract $1 \mathrm{~b}$, line 18), which is now treated as carrying a complaint. The first TCU in lines 38-39 provides a disaffiliative stance. Treating Daniele's turn as conveying that his inability to go home was the fault of a third party, Barbara claims that instead it was, at least partially, Daniele's own fault (in the construction "dipe:nde un po' anche da $\uparrow \underline{t e}: "$, which can be literally translated into "it-depe:nds a bit also on $\uparrow$ you", and idiomatically into "it's also a bit $\uparrow$ your fault").

By introducing a new TCU in latched position (line 41), Barbara exhibits that she is not ready to leave the floor. Instead, she invites Daniele to explain why he hasn't "gone ho:me anymore". This interrogative can be understood as a challenge of Daniele's complaint (Koshik 2003; Monzoni 2008), providing him with an opportunity to admit that the complained-of situation was his fault. This interpretation can be briefly elaborated upon. The understanding of Barbara's inquiry in line 41 as a challenge is supported by its positioning after the TCU that has already established Barbara's disagreement with Daniele's complaint and that has already proposed the resident as being at fault (lines 38-39). Furthermore, the interrogative references a subject "over which the questioner has greater claim to knowledge" (Koshik 2003, 72), as indexed in the first TCU (lines 38-39). Herein lies the challenge: the interrogative provides for Daniele to elaborate on the circumstances that lead to the complained-of situation (not going home) while making available that Barbara already knows what these circumstances are and that they do not warrant Daniele's complaint against his father.

Due to the focus of this chapter on responses to complaints, I cannot provide a full account of the trajectory that leads to the delivery of Barbara's disaffiliative stance toward Daniele's complaint (in lines 75-79). However, it is worth observing that this trajectory puts Daniele under increasing pressure to admit his being at fault. From line 43 to 59 Daniele attempts different answers, which are treated as inadequate by Barbara. As a result, the interrogative in line 41 and its re-doings (lines 50, 54-55, 66-67) appear to point to a very specific, 'already known' answer. Let us consider the re-doing of the interrogative in lines 54-55. This is a bit complicated, because the transcribed turn " $\downarrow$ ci devi andare con l'operatore?" (“ $\downarrow$ you must go there with the worker?") can be read as a directive, not as an interrogative. However, careful listening of the recording reveals that the " $\downarrow c i$ " component in this turn has the same downward intonation (at least impressionistically) as the " $\downarrow$ non" component in line 50, making the turn in lines 54-55 sound as another version of the previous interrogative, where the initial "ma per $\uparrow \underline{c h e ́}$ " ("but $\uparrow \underline{w h y ") ~ c o m p o n e n t ~ h a s ~ b e e n ~ o m i t t e d . ~}$ This is confirmed by Daniele's "perché"("because")-initiated response in line 57, which treats the previous turn as a why-interrogative. The particular version in lines 54-55 is revealing, since it is designed to provide Daniele with a piece of information that should help him grasp the desired answer: when he goes home to visit his father, Daniele does not go on his own, he is accompanied by one of the staff members. The answer finally treated as the expected and 'right' one comes in line 69. It makes available that, when he goes home to visit his father, Daniele does not want to come back to the TC anymore and, by implication, that this creates a problem (which is dealt with by having one of the staff members accompany him and make sure that he comes back to the TC after the visit). The answer conforms to the format of Barbara's why-prefaced turns (it starts with "perché" ["because"]), however it is also responsive to the challenges, which they implement, by delivering an admission of responsibility (Schegloff and Lerner 2009). In line 71, Barbara utters a token that indexes Daniele's answer as something rather obvious, to which Barbara has independent epistemic access (Heritage 2005).

From this point, Barbara orients to the relevance of drawing 'logical' conclusions from Daniele's answer. Daniele has a chance to provide them in the gap at line 72 and in the gap at line 74, positioned after the "so you see?" in line 73, which explicitly invokes the relevance of formulating the upshot of the provided explanation/admission of responsibility. In the face of 
Daniele's silence (line 74), Barbara proceeds to formulate the upshot on her own, through the turn extending from line 75 to line 79 . I focus on two related aspects of this turn.

The first remark is that Barbara overtly disaffiliates with Daniele (the complainant) and affiliates with Daniele's father (the complaint-target). By speaking on Daniele's father's behalf, she tries to deflect the blame away from him. Although this turn starts with a denial-like construction ("non è.: che tuo papà non ti vo:glia." ["it is: not that your dad doesn't wa:nt you."]) its interactional import resonates with the 'not at fault' denials described by Dersley and Wootton (2000; see also Monzoni 2009). Barbara does not deny that Daniele was forbidden to go home on previous occasions. She denies that Daniele's father can be blamed for this. She goes on to sympathize with the complaint-target (lines 75-76: "è che dopo tuo papà::, (0.3) fa fati $\uparrow$ ca a farti venir via:! ["it's that afterwards your da::d, (0.3) has difficul $\uparrow$ ty making you go away:!']). In this way, she puts some relational distance between herself and the complainant and instead she 'teams up' with the complained about third party (Heinemann 2009).

The second aspect relates to the resemblance between Barbara's response and 'not at fault' denials. 'Not at fault' denials "are organized so that in an implicit way complainees confirm that the complained-of action in some form has taken place" (Dersley and Wootton 2000, 381-382). The case is different here since, while deflecting the blame from the complained about third party, Barbara also shifts it to the resident ("per cui dipende un po' anche da te Daniele *se non vai a casa* $\underline{e . h}$ ?" ["so it's also a bit your fault Daniele *if you're not going home* e:h?"], lines 78-79). The claimed reason for Daniele's inability to go home is that he did not behave properly in the past. By shifting the blame to the resident, Barbara also strongly undermines the assessment that Daniele invoked in order to warrant his complaint in extract 1a, namely, that his father does not want him to go home. Barbara ties her response to Daniele's original complaint (see extract 1a, line 7: "mio papà non vuole?" ["my dad doesn't want?']), by embedding the same words in the double negative clause "non è : che tuo papà non ti vo:glia." ["it is: not that your dad doesn't wa:nt you."] (extract 1c, line 75). Again, Barbara does not deny that Daniele was deprived of the opportunity to go home. By shifting the blame to him, she denies that this event legitimately constitutes a complainable.

This example illustrates another way of implementing the restriction on affiliation. By undermining the grounds for Daniele's complaint, Barbara sequentially deletes the relevance of affiliating with the resident's complaint. Since, by the end of extract 1c, Daniele is deemed to be responsible for his own inability to go home, he cannot expect the staff members to sympathize with him and to 'side against' his father. Extract 1c also provides some insight into the kind of institutionally-relevant concerns that might motivate the staff members to confine themselves to non-affiliative responses to residents' indirect complaints. It is made available to us that the staff members are involved in the management of Daniele's visits to his father. The implication is that, by affiliating with Daniele's complaint, they could find themselves in the paradoxical situation of siding against a third party (Daniele's father) with whom they already collaborate in order to foster Daniele's compliance to the rehabilitation programme.

\section{Summary}

What I have shown so far is that the staff members can work to circumvent (extract 1a and 1b) or to neutralise (extract 1c) the interactional expectation of affiliating with the residents' indirect complaints. These findings are not yet enough to claim that the staff members orient to a restriction on affiliation in indirect complaint sequences, since they do not rule out the possibility that, on other occasions, the staff members actually affiliate with the residents' third party complaints. I fill this gap of evidence in the next section by providing a more direct display of the staff members' orientation to affiliation as a practice that should be avoided. 


\section{A deviant case}

In this section, I analyse a deviant case in order to provide further evidence for the proposed restriction on affiliation. Specifically, I show how, following a display of affiliation to a resident's indirect complaint by one of staff members, other actions are deployed that limit its sequential implicativeness.

In the following example, staff member Barbara is dealing with a resident's complaint about the medicines he has been prescribed. Franco is the resident's name (R-Fra in the transcript). I show a long transcript in order to track the trajectory leading from the resident's complaint to the candidate case of affiliation, which is produced by staff member Massimo in extract 3c.

Before the beginning of extract 3a, Franco has been asked about how he feels and he has said that he does not feel very well because he has some "strange thoughts". Following some inquiries by Barbara, Franco has also confirmed that he talked to his psychiatrist about this problem.

\section{(3a) Medication}

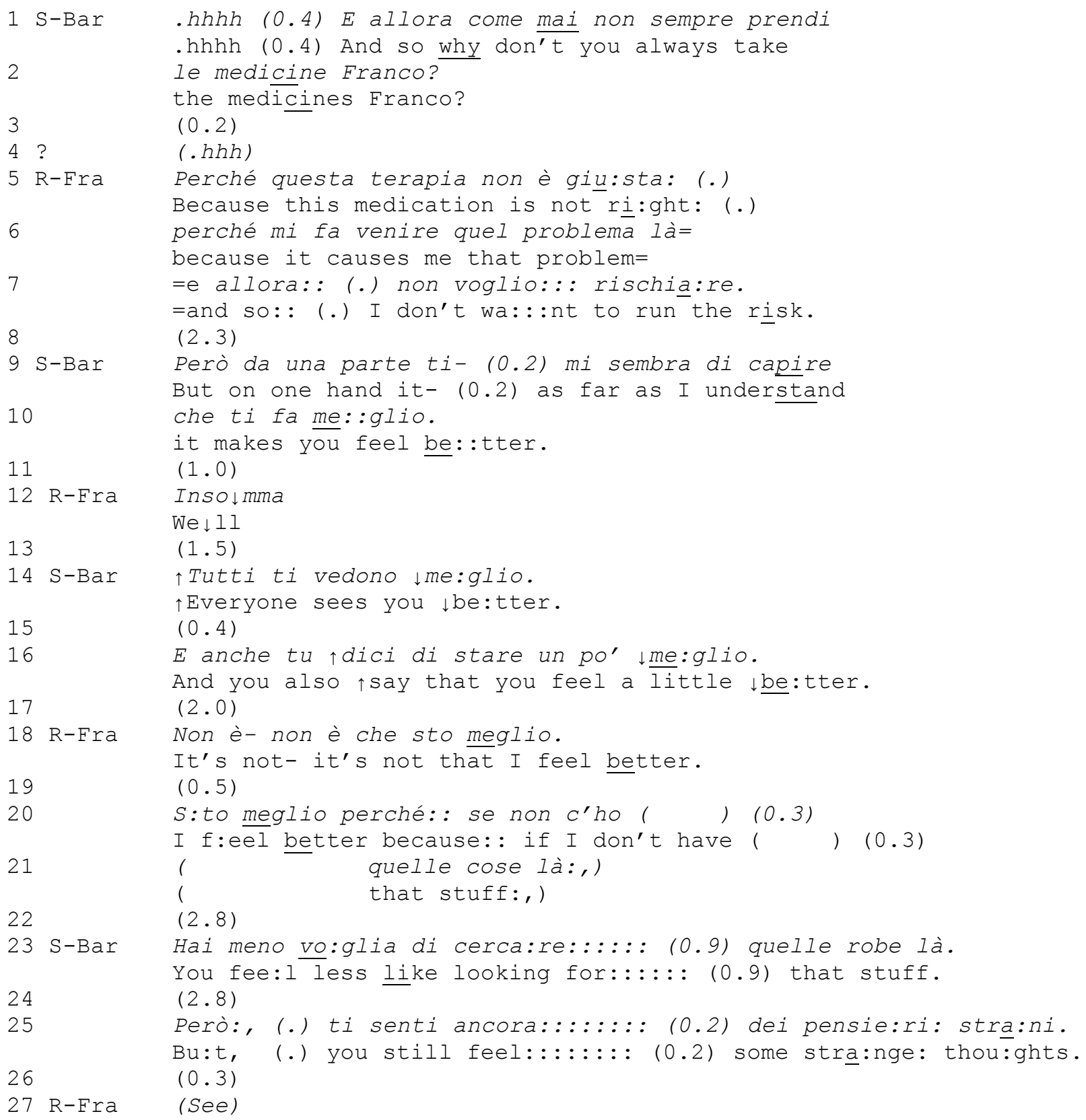




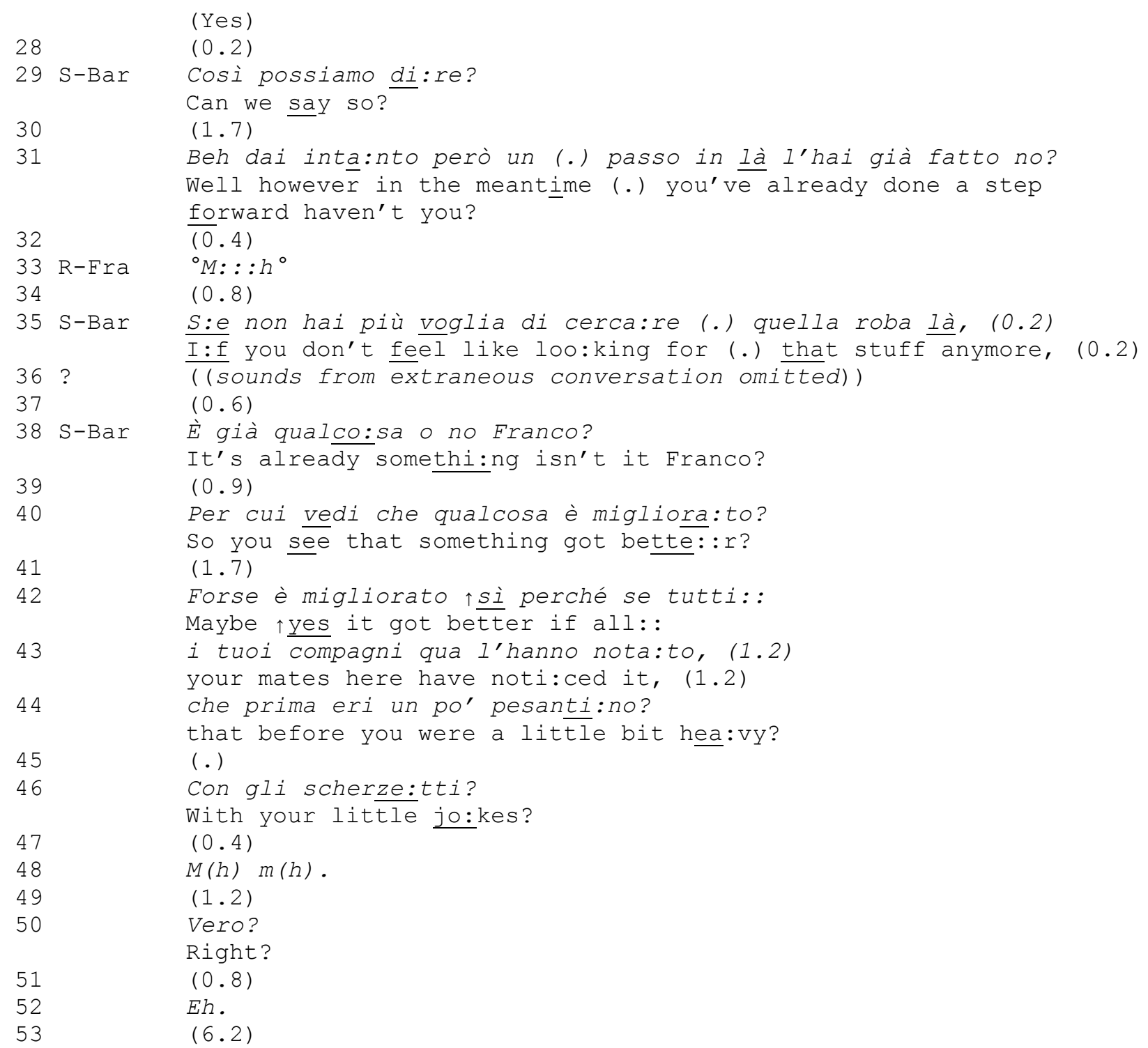

Barbara's account solicitation in lines 1-2 occasions Franco's complaint about the medication in lines 5-7. From line 9, Barbara disaffiliates with the complaint, but in a milder form than the one analysed in the previous section: she tries to mitigate the resident's complaint by counterbalancing it with more positive facts about the medication. Following a hedging response by Franco (line 12), Barbara carries on her attempt to align the resident to a more positive view about the medication (lines 14-16). Franco's disagreement (lines 18-21) is followed by Barbara's attempt to realign herself with the resident's perspective (lines 23-25). This practice consolidates a step-bystep shift from the topic of medication. However, Barbara also carries on her attempt to counterbalance the complaint and to promote a more positive view about the situation (see in particular lines 38-42). Eventually, Franco's lack of participation leads to a lapse (line 53) which could constitute a point of topic closure. Nevertheless, following Massimo's in-breath in line 54 of extract 3b, Barbara resuscitates the topic, focusing on Franco's refusal to take the medication.

(3b) Medication

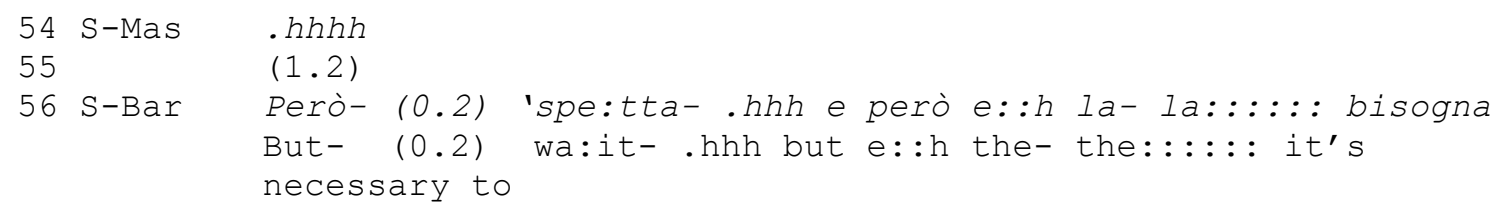




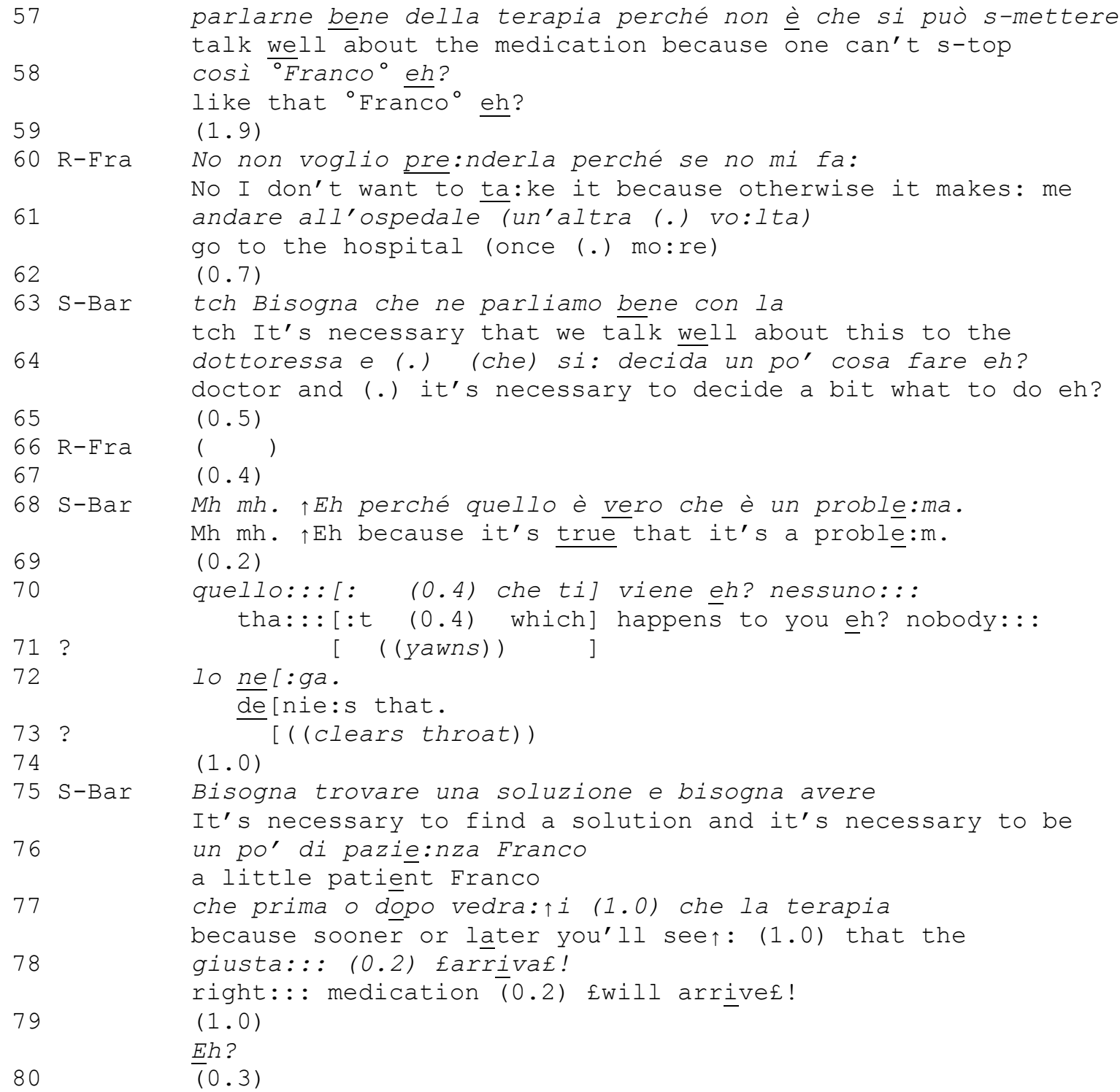

In lines 56-58, Barbara does not orient to the complaint-implications of Franco's comment about the medication (see extract 3a, lines 5-6), but to Franco's expressed refusal to take the medication as a 'problem to be solved' (see the analyses of extracts $1 \mathrm{~b}$ and 2 in this chapter). This occasions an overt rejection, accompanied by another complaint about the medication (lines 60-61). Barbara persists in presenting Franco's noncompliance to the medication as a problem that needs to be dealt with (lines 63-64). After Franco's non-hearable production in line 66, Barbara goes on to acknowledge Franco's perspective. In line with the main purpose of this chapter, I observe that this cannot be considered as a case of affiliation, in which the staff member effectively embraces the resident's perspective. Due to its embeddedness in a trajectory aimed at persuading Franco to cooperate with the psychiatric service, instead of simply refusing to take the medication (see in particular lines 57-58 and 63-64), this display of understanding of Franco's concern sounds like a 'momentary concession' (on concessions, see Heinemann and Matthews, this volume). The optimistic projection in lines 77-78 also seems ill-fitted to the seriousness of Franco's concern (see lines 60-61). My feeling that this display of sympathy is an instrumental attempt to facilitate Franco's cooperation is subsequently confirmed by the "but"-onset of Barbara's aborted turnbeginning in line 81 of extract 3c, which seems to forecast a move toward disaffiliation. Overlapping Barbara's turn-beginning and, possibly, preventing the provision of a projectable disaffiliation, Massimo produces the affiliative stance that constitutes my focus of attention in this section. 
(3c) Medication

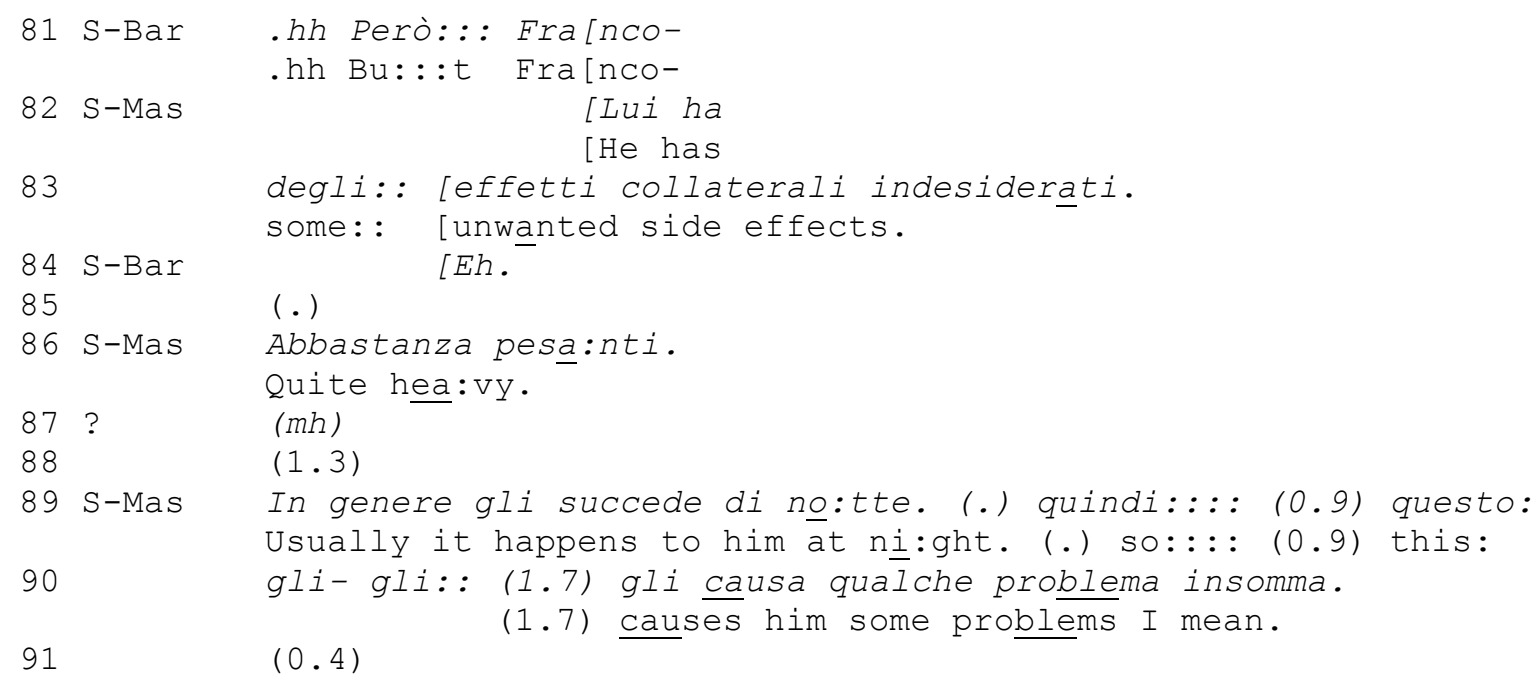

From line 82, Massimo provides an affiliative stance towards Franco's assessment of the medication. Massimo's description of "unwanted side effects" (line 83) validates Franco's negative experience about the medication as a recognizable medical condition. By volunteering details ("in genere gli succede di no:tte." ["usually it happens to him at ni:ght."]), Massimo displays independent access to Franco's problem, enhancing the feeling that it is not only a merely 'subjective' complaint (Edwards 2005). Massimo also provides an assessment of the seriousness of the side effects (line 86).

While Massimo supports the resident's assessment that the medication has negative effects on him, he does not go so far as to blame someone (like Franco's psychiatrist) for this situation, nor does he propose any remedial course of action. However, the positioning of his affiliation, at a point where Barbara's turn-beginning (line 81) can project the type of stance that she is going to provide, suggests that Massimo's intervention is introduced as a corrective to Barbara's ongoing line of action. Specifically, Barbara's intervention, with its focus on persuading the resident to cooperate instead of simply refusing to take the medication, might fail to properly grasp the seriousness of Franco's complaint. Massimo's affiliation to Franco's complaint might be produced to provide Barbara with an opportunity to redirect her line of intervention from a focus on Franco's noncompliance to medication to a focus on Franco's negative experience with the medication. At this point, Barbara has at least two options: she can modify her previous line of action or she can persist in it.

(3d) Medication

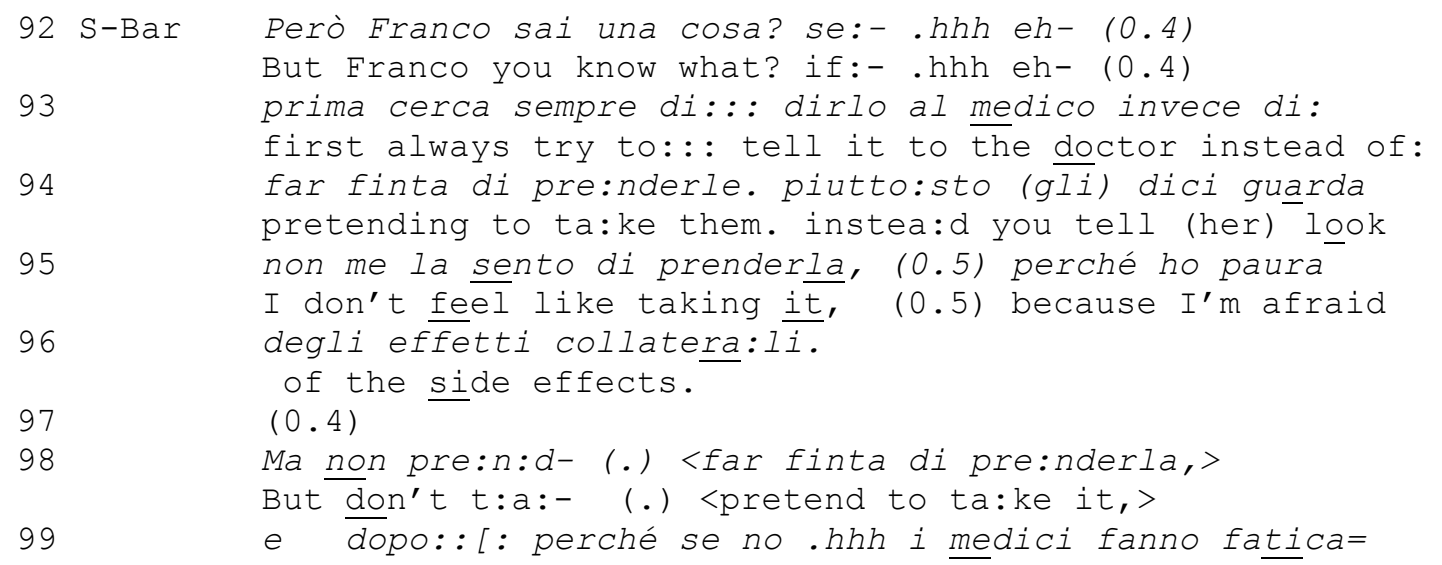




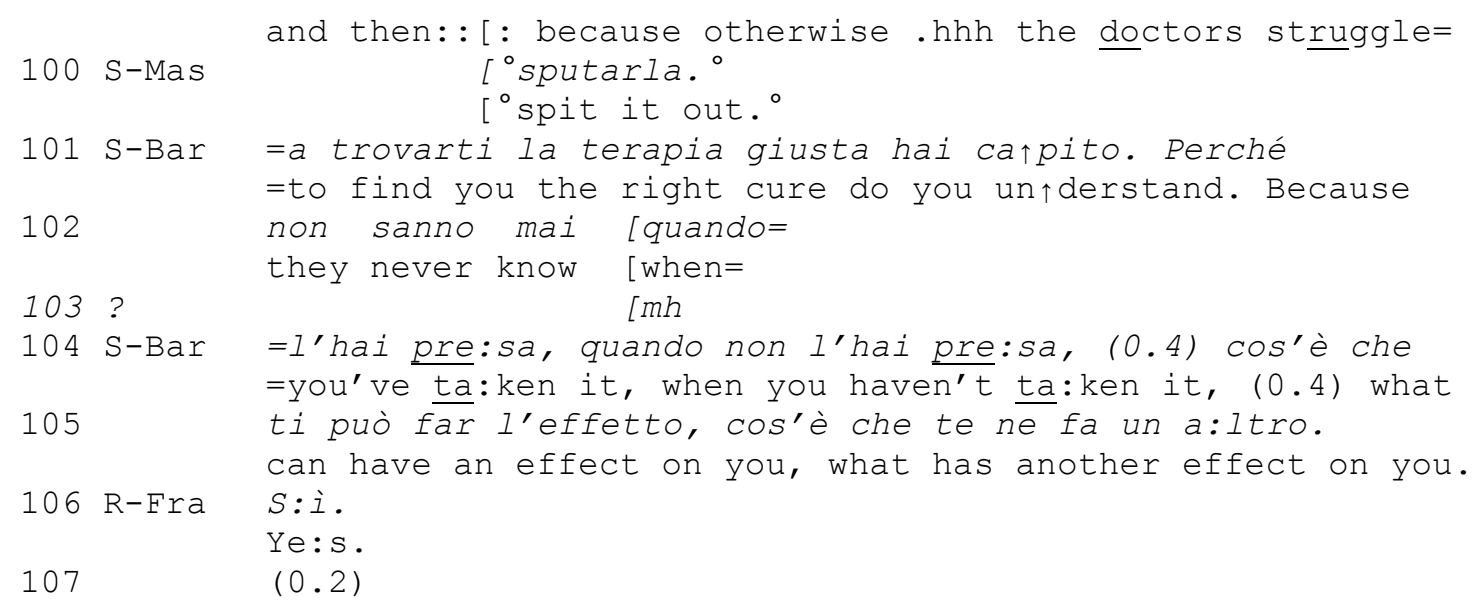

Barbara's "but"-prefaced turn, starting in line 92, is occupied by another attempt at problemresolution, by directing Franco to talk to his doctor about his difficulties with the medication. This is a kind of undertaking to which Barbara was already committed before Massimo's intervention in extract 3c. I am concerned with some practices that are embedded in Barbara's turn. First, her solution-proposal carries some degree of recognition of Franco's problem, insofar as Barbara references the side effects of the medication as, at least, something worth taking to the doctor's attention. However, Barbara's invitation to consult the doctor is also accompanied by the formulation of a resident's transgression: Franco reportedly pretends to take the medication (lines 93-94). As extract 1c in this chapter exemplifies, formulations of residents' transgressions are a constituent of staff members' displays of disaffiliation to their complaints. Furthermore, Barbara affiliates with the possible targets of Franco's complaint, namely, "the doctors" who "struggle" to find the right cure for him (lines 99-100). Like in extract 1c, it is not the complainant but the target of the complaint who receives the staff member's sympathy. Finally, since it is precisely because of Franco's lack of cooperation (he gets rid of the medication while pretending to take it) that the doctors struggle to find the right cure for him, there is also the implication that the complained-of situation (the side effects of medication) could actually be the resident's own fault. As exemplified in extract $1 \mathrm{c}$, finding the resident at fault is a device that the staff members resort to in order to relieve the complaint-target(s) of the blame explicitly or implicitly apportioned on them by the resident's complaint.

These elements lead us to observe that, following Massimo's display of affiliation towards Franco's complaint, Barbara works to restore a scenario where: (a) the resident alone is made accountable for his own complaint; (b) there is no indication that the staff support his complaint; (c) there is the implication that the complained-of situation is the resident's own fault. To further support my interpretation of Barbara's line of action, I notice that she proposes that Franco tells the doctor "I'm afraid of the side effects" (lines 95-96). Unlike in Massimo's formulation (see extract $3 \mathrm{c}$ ), the resident's problem is not referenced as an intersubjectively validated concern, but as a subjective concern for which the resident alone is accountable.

These features fit with the proposed restriction on affiliation. While showing some degree of cooperativeness (Barbara concedes that Franco talk to the doctor about his concerns with the medication), Barbara manages to distance herself from Franco's complaint. Not only does she avoid embracing it but, by restoring a framework where the focus of attention is the resident's lack of compliance to the medical prescription (not the possible mistreatment that he received), Barbara neutralises some of the implications of Massimo's affiliation to Franco's complaint. She thus exhibits an orientation to affiliation as a practice that should be avoided following a resident's indirect complaint. It can also be noticed that Massimo does not make any further attempt to support Franco's stance. Instead, he collaborates in the formulation of the resident's transgression, in line 100. By doing so, Massimo accepts Barbara's move to restore a framework where the staff members maintain a certain relational distance towards the resident. In this participation framework, 
not only do the staff members avoid embracing the residents' complaints, but they also 'team up' with the complaint-targets, while at the same time pointing to the residents' faults or transgressions.

\section{Restricted responses to indirect complaints and institutionally-relevant identities}

In this chapter I have examined staff members' responses to residents' indirect complaints in a mental health TC in Italy. I have described three practices that the staff members employ to deal with the residents' complaints and I have showed how these practices reflect a restriction on affiliation. While by ignoring the residents' turns carrying complaints or by avoiding addressing the complaint-implicative aspects of those turns the staff members avoid conveying their evaluation of the complained-of events, by undermining the resident's complaints the staff members display a disaffiliative stance. The fact that the staff members can engage in substantial interactional work to undercut the grounds for the residents' indirect complaints (see extract 1c) reveals that their main practical concern is not with neutralism or impartiality (see Weatherall, this volume), but with the avoidance of affiliation.

A question worth addressing is why the staff members confine themselves to non-affiliative responses to indirect complaints. The staff members seem to orient to the weekly meetings as a public space where their responses to the residents' complaints have the potential to remain 'on record'. The provision of an affiliative stance would commit them to publicly acknowledge that the residents have suffered a mistreatment. Instead, they provide for the residents to either to drop their complaints (see extract $1 \mathrm{~b}$ ), or to accept responsibility for occasioning the negative circumstances about which they complained in the first place (see extracts 1c and 3d). A consequence of the staff members' restriction to non-affiliative responses is that the residents' views about the possible negative effects of the treatments, procedures and practices that form their rehabilitation programme, never become part of a publicly displayed, 'on record' commitment to review or to adapt those treatments, procedures and practices (see also Mortari and Pino 2013).

At the same time, the staff members' avoidance of affiliative responses goes beyond a concern with cautiousness and appears to be a way of orienting to the broader socio-relational order of the mental health service in which the residents' rehabilitation programme is embedded, and in which the staff members act as intermediaries. Staying with the examples in this chapter, the staff members cannot decide what medication Franco has to take (see extracts 3a-3d), nor can they decide whether Daniele can go home (see extracts 1a-1c). These are the prerogatives of Franco's psychiatrist and Daniele's father, respectively. However, the staff members seem to have some stake in these matters. Since they are responsible for checking that Franco takes the medication as prescribed, the staff members have some interest in having the resident cooperate and discuss his problems with the psychiatrist, instead of simply refusing to take the medication. In a similar vein, they are responsible for ensuring that Daniele come back to the TC after his visits to his father.

As institutional representatives who engage in everyday, prolonged supervision of the residents' conduct, the staff members are accountable for fostering the residents' compliance to the decisions of other agents, who engage with them more sporadically but who play a key role in the management of the rehabilitation programme, such as other mental health professionals and family members. In this respect, the staff members' responses to the residents' indirect complaints implement their identity of intermediaries, whose task is to maintain the normative order that underlies the relational architecture of the TC. This is indexed, for example, in the practice of referencing the residents' transgressions in response to their complaints (see extracts $1 \mathrm{c}$ and $3 \mathrm{~d}$ ).

The staff members' disaffiliative responses to the residents' complaints constitute a major difference between the setting of the TC and other institutional settings where the professionals' conduct exhibits restrictions on disaffiliating with the clients (see among others Heinemann and Matthews, this volume, and Zanini and Gonzales, this volume). By disaffiliating with the residents, the staff members demonstrate solidarity with relevant absent third parties, who are involved in the 
management of this mental health service. In this respect, the staff members' disaffiliative responses can be seen as manifesting of a concern with maintaining and reinforcing a network of alliances that extends beyond the proximal context of the staff-residents interactions.

\section{Contribution to the understanding of restricted activities}

My study contributes to the understanding of restricted activities by investigating a setting where a restriction in the range of activities being employed is not the result of formal constraints. There is nothing in the service policies of this TC (as explored through the examination of documents, interviews, informal exchanges with the staff members and prolonged field observation) suggesting that the staff members are formally banned from affiliating with the residents' complaints (see Drew and Heritage 1992). In 'formal' settings, such as news interviews or courtrooms, activity restrictions can ultimately be understood with reference to the operation of a formal turn-taking system, which places constraints on the turn-types that can be uttered in specific sequential positions by different speakers, in ways that reflect (and reflexively constitute) the asymmetrical identities and prerogatives of professional and lay participants (Drew 1992; Greatbach 1992). The mental health TC where I carried out my research can be characterised as a 'less formal' setting, where observable "asymmetries are apparently not the products of turn-taking procedures that are normatively sanctionable" (Drew and Heritage 1992, 27-28). I argue that the staff members orient to the availability of different response-types at the level of sequence organisation, which carry different consequences and implications for the kind of job that they try to accomplish, and that they select non-affiliative responses as the appropriate way of locally addressing some core concerns that are inherent in their institutionally-relevant identity of intermediaries, although not formalized as such by the service policies (see Chevalier, this volume).

This interpretation can account for why the restriction is manifested across a multiplicity of practices. It is not that the staff members have been formally instructed on how to address the residents' complaints; they avoid affiliation as a way of navigating the contradictions immanent in their role of intermediaries, and they do so in ways that are sensitive to local contingencies. A methodological implication of my study is that, in order to provide evidence for an interactional restriction in a less formalised institutional setting, it may be necessary to account for the variation in the ways that the restriction is locally manifested. In the case of my study, the identification of a deviant case was decisive in order to support the claim that the staff members orient to affiliation as a type of stance that should be avoided in response to the residents' indirect complaints.

A related issue is: why do the staff members implement the restriction on affiliation in the specific ways reported in this chapter? The restriction on affiliation is not always manifested through disaffiliation: sometimes, the staff members simply avoid displaying a stance. It might be that, in certain circumstances, it is more economical and practical for them to let the complaints pass and to continue an ongoing activity, as in extract 1a. Aspects of the resident's turn or the surrounding conversational environment can make available such an opportunity. I also observe that there are issues of personal style: Barbara seems more inclined to display overt disaffiliation towards the residents' complaints, while Massimo more often disattends to them. In any event, the variation in the ways that the staff members locally manage the restriction on affiliation does not compromise the robustness of my central finding: the staff members avoid agreeing, embracing or otherwise supporting the residents' evaluations of the complained-of events. The restriction on affiliation appears as persistent and consequential. With regard to persistence, the restriction informs the staff members' conduct across a range of conversational contingencies. For instance, it holds across circumstances where the residents explicitly point to a third party's responsibility in causing them some harm (as in extract 1a) and where the residents confine themselves to describing a negative state of affairs, without overtly blaming anyone (extract $3 \mathrm{a}$ ). As the deviant case analysis shows, the restriction on affiliation also holds when elements are brought to the conversational 
surface that could support a resident's conveyed stance (extract 1c). With regard to consequentiality, the restriction can shape the conduct of the staff members in tangible ways. For instance, the analysis of extract $1 \mathrm{~b}$ suggests that, if the staff members wish to affiliate with the residents, they must target some aspect of their turns other than their complaint-implicative elements. Massimo displays a degree of cooperativeness toward Daniele by selecting to address his turn as carrying a problem presentation, not a complaint. This enables Massimo to minimise the hearability of his response as supporting the resident's grievance (on the minimisation of the hearability of a turn as performing a specific action, see Butler, Danby and Emmison, this volume). This example shows how the restriction on affiliation can shape and constrain the implementation of one of the core tasks that the staff members are expected to carry out as mental health workers: supporting the residents through their difficulties.

\section{Notes}

${ }^{1}$ The rising intonation with which Daniele's name is uttered al line 30 of extract 1a is hearable as a marked 'continuing' intonation, signalling that the reading of the list is not over yet. It is not hearable (nor it is treated by the co-participants) as a request for confirmation addressed to Daniele.

${ }^{2}$ An anonymous reviewer observed that 11. 3-4 possibly display Massimo's assumption that the residents who 'want' to go home 'can' go home, and that Daniele might be picking up on that at 11. 6-7 by presenting the inability to go home as a problem to be solved. The reviewer further suggests the possibility that this is also hearable as a direct complaint against the staff "for not doing something about a (presumably) long term and ongoing problem". Although space limitations prevent from addressing this issue at length, it is worth observing that the staff members' responses do not exhibit an orientation to this turn as a direct complaint. At the same time, as we will see, staff member Barbara sides with the complaint-target (Daniele's father) (11. 75-76 of extract 1c). This suggest that, although the resident's turn is treated as embedding an indirect complaint (as I will soon demonstrate), it is nevertheless treated as pointing to a situation where the staff members' responsibility seems to be at least co-implicated (this possibility is further discussed in Pino and Mortari 2013).

${ }^{3}$ The idiomatic translation is meant to capture a possible meaning of Dina's turn across lines 3-4. Literally, she says "[she] does not see the Euros

as they are made". Through the reformulation at 1.8 ("that I get it wrong") Dina clarifies that at 11. 3-4 she has referred to her alleged incompetence in the appraisal of the Euro currency (what seems to have happened here is that a medical or a legal board is considering her as unable to correctly use the Euro, and this might be partly because the Euro currency had not yet been introduced when she entered the psychiatric service several years before the recorded meeting).

${ }^{4}$ This item has no meaning in Italian or in the local dialect (at least none that I can identify). Linda recurrently produces speech that apparently has no identifiable meaning in ordinary language. The other participants involved in this sequence do not appear to attend to what Linda is saying here.

${ }^{5}$ This deictic refers to the TC (where the meeting is taking place).

\section{References}

Bolden, Galina B. 2009. "Implementing incipient actions: The discourse marker 'so' in English conversation." Journal of Pragmatics 41: 974-998.

Crescentini, Alessandro, Franco De Felice, and Claudio Tonzar. 2004. L'educatore e la riabilitazione psichiatrica [The educator and the psychiatric rehabilitation]. Roma: Carocci.

Dersley, Ian, and Anthony Wootton. 2000. "Complaint Sequences Within Antagonistic Argument." Research on Language and Social Interaction 33: 375-406. 
Drew, Paul. 1992. "Contested evidence in courtroom cross-examination: the case of a trial for rape." In Talk at work: interaction in institutional settings ed. by Paul Drew, and John Heritage, 470-520. Cambridge: Cambridge University Press.

Drew, Paul. 1998. "Complaints about transgressions and misconduct." Research on Language and Social Interaction 31: 295-325.

Drew, Paul, and John Heritage. 1992. “Analyzing talk at work: an introduction.” In Talk at work: interaction in institutional settings ed. by Paul Drew, and John Heritage, 3-65. Cambridge: Cambridge University Press.

Drew, Paul, and Traci Walker. 2009. "Going too far: Complaining, escalating and disaffiliation." Journal of Pragmatics 41: 2400-2414.

Edwards, Derek. 2005. "Moaning, whinging and laughing: the subjective side of complaints." Discourse Studies 7: 5-29.

Greatbach, David. 1992. "On the management of disagreement between news interviewers." In Talk at work: interaction in institutional settings ed. by Paul Drew, and John Heritage, 268-301. Cambridge: Cambridge University Press.

Heinemann, Trine. 2009. "Participation and exclusion in third party complaints." Journal of Pragmatics 41: 2435-2451.

Heinemann, Trine, and Véronique Traverso. 2009. "Complaining in interaction." Journal of Pragmatics 41: 2381-2384.

Heritage, John. 2005. "Cognition in discourse." In Conversation and Cognition ed. by Hedwig te Molder, and Jonathan Potter, 184-202. Cambridge: Cambridge University Press.

Jefferson, Gail. 1988. "On the Sequential Organization of Troubles-Talk in Ordinary Conversation." Social Problems 4: 418-441.

Koshik, Irene. 2003. "Wh-questions used as challenges." Discourse Studies 5: 51-77.

Laforest, Marty. 2009. "Complaining in front of a witness: Aspects of blaming others for their behaviour in multi-party family interactions." Journal of Pragmatics 41: 2452-2464.

Mandelbaum, Jenny. 1991/1992. "Conversational Non Cooperation: An Exploration of Disattended Complaints." Research on Language and Social Interaction 25: 97-138.

Monzoni, Chiara M. 2008. "Introducing direct complaints through questions: the interactional achievement of 'pre-sequences'?" Discourse Studies 10: 73-87.

Monzoni, Chiara M. 2009. "Direct complaints in (Italian) calls to the ambulance: The use of negatively framed questions." Journal of Pragmatics 41: 2465-2478.

Mortari, Luigina, and Marco Pino. 2013. "Conversational pursuit of medication compliance in a Therapeutic Community for persons diagnosed with mental disorders". Disability and Rehabilitation Early Online: 1-12.

Pino, Marco, and Luigina Mortari. 2013. 'Beyond neutrality: Professionals' responses to clients' indirect complaints in a Therapeutic Community for people with a diagnosis of mental illness". Communication \& Medicine 10: 213-224.

Ruusuvuori, Johanna, and Pirjo Lindfors. 2009. "Complaining about previous treatment in health care settings." Journal of Pragmatics 41: 2415-2434.

Sacks, Harvey. 1992. Lectures on Conversation. 2 vols. Oxford: Blackwell.

Schegloff, Emanuel A. 1988. "Goffman and the analysis of conversation." In Erving Goffman: Exploring the interaction order ed. by Paul Drew, and Anthony Wootton, 89-135. Cambridge, England: Polity Press.

Schegloff, Emanuel A. 1996. "Turn organization: one intersection of grammar and interaction." In Interaction and grammar ed. by Elinor Ochs, Emanuel A. Schegloff, and Sandra A. Thompson, 52-133. Cambridge: Cambridge University Press.

Schegloff, Emanuel A. 2005. "On Complainability.” Social Problems 4: 449-476.

Schegloff, Emanuel A. 2006. "On possibles." Discourse Studies 8: 141- 157.

Schegloff, Emanuel A. 2007. Sequence organization in interaction: a primer in conversation analysis I. Cambridge: Cambridge University Press. 
Schegloff, Emanuel A., and Lerner, Gene H. 2009. "Beginning to Respond: Well-Prefaced Responses to Wh-Questions." Research on Language \& Social Interaction 42: 91-115.

Stivers, Tanya. 2008. "Stance, Alignment, and Affiliation During Storytelling: When Nodding Is a Token of Affiliation." Research on Language \& Social Interactio 41: 31-57.

Stokoe, Elizabeth. 2009. "Doing actions with identity categories: complaints and denials in neighbor disputes." Text \& Talk 29: 75-97.

Traverso, Véronique. 2009. "The dilemmas of third-party complaints in conversation between friends." Journal of Pragmatics 41: 2385-2399. 